One message of the paper is that a low degree of phylogenetic certainty does not prohibit a successful comparative study. This is an area that needs further investigation, however, particularly as the bootstrapped trees are not themselves altogether independent, so compromising the tests of significance for the
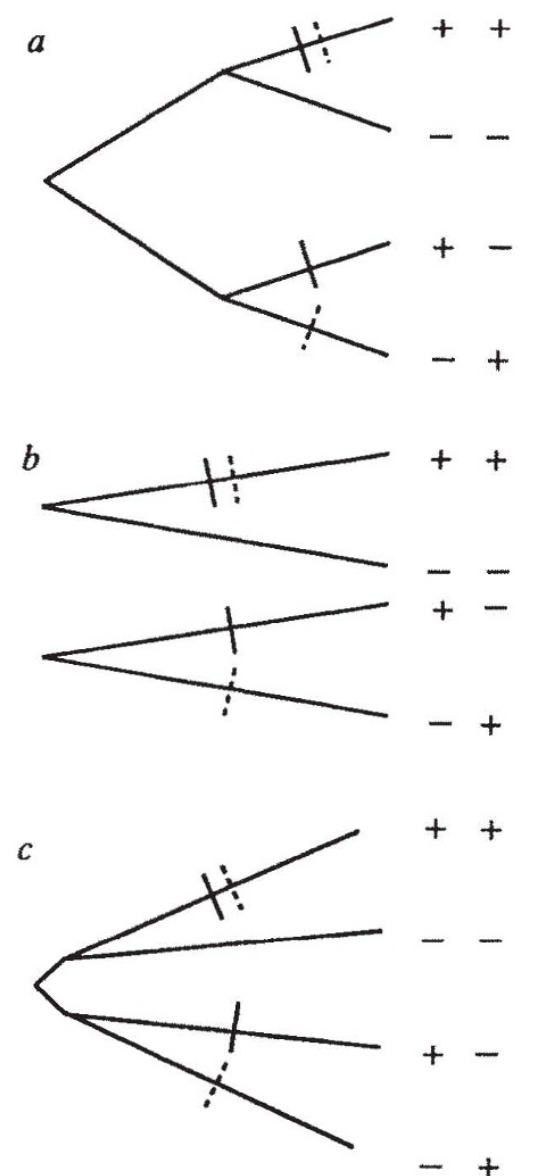

FIG. 2 Alternative patterns of relationship between two variables as might be found in phylogenetic analyses: $a$, typical tree; $b$, paired-species analysis; $c$, relatively simultaneous radiation.

mean contrast correlations. It would also be reassuring to see what the distribution of contrast values would be for completely arbitrary trees.

A potential problem in the use of a phylogeny from any single DNA sequence, and mitochondrial DNA in particular, is that it need not necessarily reflect the pattern of speciation itself $^{10}$. But errors arising this way would presumably tend to reduce the strength of true contrast correlations rather than to create them as artefacts, so in this respect the approach is statistically conservative.

It is sometimes possible to control for ancestry without having to use an explicit phylogeny by using a paired-species analysis ${ }^{11}$. In this, pairs of related species are identified which differ with respect to a variable of interest $(b$ in Fig. 2). If enough such pairs can be iden- tified then probabilities of association can be obtained assuming phylogenetic independence. In this way it has been shown that, as predicted, birds breeding at higher density have significantly higher rates of both intra-pair and extra-pair copulations than more solitary species $^{12}$.

One criticism of the comparative approach is that attempts to increase statistical independence may reduce the sample size and make it harder to reject an incorrect hypothesis. There is then a danger that fervent statistical rigour might obscure interesting patterns; after all, Darwin and his successors managed very well without worrying about confounding variables (but see ref. 13). Broad and even nonstatistical analyses therefore remain a good starting point for looking at evolutionary trends, although ultimately they are not totally convincing. It is noticeable, however, that phylogenies such as that for the warblers often point to ancient, quick bursts of speciation. Although this might result artefactually from a loss of resolution due to the number of nucleotide substitutions approaching saturation, it could be that it is a real response to irregular and major biogeographical events. This could mean that divergence is often really rather umbrella-like ( $c$ in Fig. 2): if the traits of interest evolve randomly through time, then withingroup analyses might not in any case be so confounded.

So which method should be used? The paired-species procedure certainly has considerable advantages, especially for studying features that have evolved in many different lineages. But where interesting traits feature in only a restricted range of taxa, or when adaptive radiation is itself being investigated, it is probably time to have a rest from worrying about statistics and to invest in a lab coat instead.

Terry Burke is in the Department of Zoology, University of Leicester, Leicester LE1 7RH, UK.

1. Harvey, P. H. \& Pagel, M. D. The Comparative Method in Evolutionary Biology (Oxford University Press, 1991)

. Brooks, D. R. \& McLennan, D. A. Phylogeny, Ecology and Behavior (Chicago University Press, 1991)

3. Richman, A. D. \& Price, T. Nature 355, 817--821 (1992).

4. Felsenstein, J. Am. Nat. 125, 1-15 (1985)

5. Ridley, M. The Explanation of Organic Diversity: The Comparative Method and Adaptations for Mating (Oxford University Press, 1983).

6. Höglund, J. Am. Nat. 134, 72-87 (1989).

7. Kocher, T. D. et al. Proc. natn. Acad. Sci. U.S.A. 86 , 6196-6200 (1989).

8. Taberlet, P. et al. Plant molec. Biol. 17, 1105-1109 (1991).

9. Sessions, S. K. \& Larson, A. Evolution 41, 1239-1251 (1987).

10. Pamilo, P. \& Nei, M. Molec. Biol. Evol. 5, 568-583 (1988).

11. Birkhead, T. R., Atkin, L. \& Møller, A. P. Behaviour 101, 101-138 (1987)

12. Birkhead, T. R. \& Møller, A. P. Biol. J. Linn. Soc. (in the press)

13. Ridley, M. Trends Ecol. Evol. 7, 37 (1992).

\section{Spread the word}

GRAFFITI, the revenge of the powerless against the powerful, disfigure ever more of our public space and transport. These scrawls are hard to remove, and no surface is safe from them. In the absence of any social solution, Daedalus has a technical fix, inspired by borophosphatepolymer glass. This material resists surface contamination. The insides of water pipes are often coated with it, as are anti-fouling surfaces at sea. Its surface partially hydrolyses to oligomer fragments which, by breaking and reforming chemical bonds to the material beneath, slowly move around. Nothing can adhere for long to such a shifty, fluid surface.

DREADCO chemists are extending this principle. They are devising other polymers whose surfaces hydrolyse or depolymerize to mobile molecular fragments. Their goal is a sort of liquidcrystal surface: hard and firm towards indentation, but viscously fluid to sideways motion. Such a surface will be always on the move, driven by aircurrents, accidental contacts, or simple brownian diffusion. A sprayed-on drawing or comment will be stirred as well. Almost before the artist has completed his creation, it will begin to blur, distort and spread. In a short while it will be evenly distributed over the whole surface, as a mild and innocent colour cast.

DREADCO's 'Shiftycoat' will revolutionize public architecture. Sprayed or daubed slogans will rapidly blur away, disintegrating in great swirls and whirls as the slowly moving surface convects and dilutes them into uniformity. Some graffiti artists will be discouraged; others will welcome this endless renewal of their creative canvas; but all will be transformed from anti-social nuisances into useful citizens. They will be painting and renovating the public facilities, for free.

The colour of this redecoration service will change slightly with each added slogan, but will probably average to a rather chic grey. The marks and scuffs left by hurrying humanity will also be uniformly spread, replacing the general tattiness of public places with a permanent cheery smartness.

Householders and interior decorators will welcome Shiftycoat too. No longer will the clean patch behind a recently moved picture betray the dirtiness of the whole room. No longer will convective dust marks slowly intensify about air ducts and radiators. The dirt will be evenly distributed, giving the place that 'just-decorated' look. Even a can' of paint thrown at the wall in a domestic squabble would be slowly spread all over it, to fade and be forgotten with the argument that propelled it. 